\title{
Physical, physiological characteristics and sport goal orientation of top Portuguese kickboxing athletes
}

Paulo SILVA*1, Miguel SILVA¹, João DUARTE ${ }^{1}$, Alexis AHMED ${ }^{1}$, Oscar TAVARES², João VALENTEDOS-SANTOS ${ }^{1}$, Joaquim CASTANHEIRA ${ }^{1,2}$, Rui SOLES-GONÇALVES ${ }^{1,2}$, Luís RAMA ${ }^{1}$, \& Manuel J. COELHO-E-SILVA ${ }^{1}$

${ }^{1}$ Faculty of Sports Sciences and Physical Education - University of Coimbra (Portugal)

${ }^{2}$ Coimbra Health School- Polytechnic Institute of Coimbra(Portugal)

\section{Introduction}

Kickboxing emerged under the influence of other martial arts and combat sports (Buse, 2009) and it is characterized by consecutive changes of direction in a large spectrum of exercising. In addition, this sport requires complex technical and tactical skills (Ouergui, et al., 2014). Several studies have been conducted in various combat sports and martial arts, in order to characterize the physiological and anthropometrical profile of the athlete; however, in the case of Kickboxing the literature is limited on small samples (Zabukovec \& Tiidus, 1995). Such information provides guidance for training interventions, performance testing and talent identification.

\section{Methodology}

The sample is composed of 10 top Portuguese athletes on pre professional stage (age: $23.4 \pm 3.1$ years, stature: $173.9 \pm 6.8 \mathrm{~cm}$; body mass: $71.3 \pm 10.1 \mathrm{~kg}$ ). Anthropometry also includes, total body volume (BV-L) obtained from air displacement plethysmography (ADP), bone mineral content (BMC-g) assessed by dual energy x-ray absorptiometry (DXA) and total body water from bioimpedance (TBW-L, 50Hz). Left ventricular mass was obtained from M-mode echocardiograms using two-dimensional images. Physiological tests included maximal aerobic running test ( $\left.\mathrm{VO}_{2} \mathrm{max}\right), 30$-s Wingate test and concentric isokinetic strength of knee extension (KE) and knee flexion (KF) at $60^{\circ} . \mathrm{s}^{-1}$ and $180^{\circ} . \mathrm{s}^{-1}$. Athlete also completed the Portuguese versions of the Task and Ego Orientation in Sport Questionnaire (TEOSQp).

\section{Results}

The mean values and respective dispersion (standard deviation) for the total sample were $46.8 \pm 8.2$

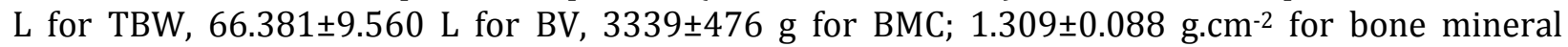
density (BMD). Percentage of fat mass were derived from three protocols and ranged from $10.9 \pm 2.3 \%$ (DXA), $9.2 \pm 2.3 \%$ (ADP), $10.5 \pm 2.9 \%$ (bioimpedance). Mean value of left ventricular mass was $180.0 \pm 39.6 \mathrm{~g}$ (internal diameter at end of the diastole: $59.6 \pm 4.2 \mathrm{~mm}$; septal wall thickness at the end of the diastole: $7.9 \pm 0.9 \mathrm{~mm}$; posterior wall thickness at the end of the diastole: $7.6 \pm 0.6$ $\mathrm{mm})$. Mean values in physiological variables reporting aerobic fitness were $4.438 \pm 0.647 \mathrm{~L}$ $\left(\mathrm{VO}_{2} \mathrm{max}\right)$. This parameter per unit of body mass was $62.5 \pm 4.3 \mathrm{~mL} \cdot \mathrm{kg}^{-1} \cdot \mathrm{min}^{-1}$. Ventilatory thresholds (VT) were $2.968 \pm 0.340 \mathrm{~L}$ (VT1) and $3.713 \pm 0.466 \mathrm{~L}$ (VT2). Regarding anaerobic fitness mean values were $970 \pm 135$ watt and $608 \pm 77$ watt respectively for the Wingate peak and mean outputs. Peak torque assessed by isokinetic dynamometer for KE and KF were $231 \pm 34$ N.m and $136 \pm 23 \mathrm{~N}$.m at 
angular speed of $60^{\circ} . \mathrm{s}^{-1}$. Respective values at $180^{\circ} . \mathrm{s}^{-1}$ were $161 \pm 32$ N.m and $108 \pm 26 \mathrm{~N} . \mathrm{m}$. The hamstrings to quadriceps strength ratio were $0.59 \pm 0.07$ and $0.67 \pm 0.10$, for the angular speeds of $60^{\circ} . \mathrm{s}^{-1}$ and $180^{\circ} . \mathrm{s}^{-1}$, respectively.

\section{Discussion and conclusion}

The first ventilatory threshold (VT1) is also described as gas exchange threshold and is interpreted as the point of transition between moderate-to-heavy intensity regimens corresponding to the intensity at which occurs the first disproportionately increment in ventilation (VE) to $\mathrm{VO}_{2}$ consumption. The second disproportionate increase in ventilation is termed the second ventilatory threshold (VT2), sometimes called the respiratory compensation threshold (RCT) and indicates an exercise intensity that can no longer be sustained for long periods, and represents the highest sustainable level of exercise intensity. VT1 and VT2 occurred at $67.4 \pm 5.7 \%$ and $83.7 \pm 6.3 \%$, respectively. Mean values for the Wingate test were slightly lower than means reported in the literature for 4 elite kickboxers (Zabukovec \& Tiidus, 1995): 1360 watt for peak output and 761 watt for mean output. However, caution is required since the present study and the values obtained from the literature did not use the same Monark model. In addition, the current study collected information at $1 \mathrm{~Hz}$ and this information is lacking in the study by Zabukovec and Tiidus (1995). The sampling rates are assumed to be an extra source of variation between studies. The study reporting Canadian elite kickboxers (Zabukovec \& Tiidus, 1995) uniquely assessed knee extension at the two angular speeds of the current study without any information about knee flexion. Mean values were 220 N.m and 168 N.m for the slower and faster speeds, respectively. The athletes of this study showed comparable results or even superior to other elite athletes of combat sports, reporting low body fat mass, good levels of BMC and BMD, high levels of aerobic power and maximum mechanical power and good levels of muscle strength in the extensors and flexors of the knee. Some of the heart dimensions are increased relative to sedentary individuals, such as in most sports. They also show high levels of motivational task orientation and a 2D:4D ratio equal to one for both hands. These results demonstrate the high physical requirements for success in Kickboxing. Information and results of this study may contain useful information for coaches.

\section{References}

Buse, G. J. (2009). Kickboxing. In R. Kordi, N. Maffuli, R. R. Wroble, \& W. A. Wallace (Eds.), Combat Sports Medicine (pp. 331-350). Springer.

Ouergui, I., Hssin, N., Haddad, M., Franchini, E., Behm, D. G., Wong, D. P., ... Bouhlel, E. (2014). Timemotion analysis of elite male kickboxing competition. Journal of Strength and Conditioning Research, 28(12), 3537-3543.

Zabukovec, R., \& Tiidus, P. M. (1995). Physiological and Anthropometric Profile of Elite Kickboxers. Journal of Strength and Conditioning Research, 9(4), 240-242.

Key words: Multi-compartment body composition; kinanthropometry; isokinetic assemssment; metabolic pathways; combat sports; kickboxing. 